Check for updates

Cite this: Mater. Adv., 2021, 2, 434

Received 27th October 2020 , Accepted 1st December 2020

DOI: $10.1039 / \mathrm{d} 0 \mathrm{ma00839g}$

rsc.li/materials-advances

\title{
Pourbaix sensors in polyurethane molecular logic-based coatings for early detection of corrosion $\dagger$
}

\begin{abstract}
Glenn J. Scerri, Jake C. Spiteri and David C. Magri (D)*
The cost of corrosion to the world economy is estimated to be in excess of US\$2.5 trillion per year. Herein we present a strategy for the early detection of corrosion using purposely designed molecules with on-board parallel processing in a polyurethane coating on mild steel. The proof-of-concept is demonstrated with perylenediimide and 4-amino-1,8-naphthalimide-based molecules that function as $\mathrm{H}^{+}, \mathrm{Fe}^{3+}$-driven AND logic gates for high acidity and oxidising conditions. The onset of corrosion is detected by an enhanced yellow-green fluorescence (>500 nm). The extent of fluorescence enhancement is viewed by confocal fluorescence microscopy. The applicability of logic-based molecules represents a method for the non-destructive and early detection of corrosion long before the metal surface suffers any permanent damage.
\end{abstract}

\section{Introduction}

Corrosion of metals and alloys is an enormous economic burden across global industries and infrastructures. ${ }^{1}$ The cost of corrosion to the world economy is estimated to be in excess of US\$2.5 trillion per year. ${ }^{2}$ A Battelle/NBS study ${ }^{3}$ estimated that $>3 \%$ of the US gross national product (GNP), or US\$276 billion (equivalent to one-half the 2019 US R\&D budget), ${ }^{4}$ is spent on corrosion-related maintenance. The US Navy and US Department of Defence spend a quarter of their maintenance budget, in excess of US\$20 billion, on corrosion. ${ }^{5}$ Given the statistics, potential cost-savings could pay staggering dividends. Therefore, new technologies for the early detection, non-destructive evaluation and prevention of corrosion contribute towards sustainable economic growth, industry competitiveness and high safety standards in-line with the United Nations Sustainable Development Goals (SDGs). ${ }^{6}$

Corrosion is initially an invisible enemy. By the time it is visible to the human eye, structural damage has already occurred. Left unchecked over years, corrosion leads to fatigue, and in the historic case of Silver Bridge, catastrophic failure. ${ }^{7} \mathrm{~A}$ small defect measuring a mere $2.5 \mathrm{~mm}$ ( 0.1 inches) in one of the eye bars (a 55-foot-long section of steel) contributed to the collapse of the steel bridge with subsequent loss of life and property.

Department of Chemistry, Faculty of Science, University of Malta, Msida, MSD 2080, Malta.E-mail: david.magri@um.edu.mt

$\dagger$ Electronic supplementary information (ESI) available: Synthesis, characterisation and spectra. See DOI: 10.1039/d0ma00839g
The standard non-destructive method for corrosion detection is the liquid penetrant test (LPT). ${ }^{1}$ Commonly used during the fabrication, manufacturing and service of metallic components, the method uses a coloured solution, known as a penetrant, which is brushed or sprayed onto a surface. After a short time, a transparent developer reagent is applied to contrast the colour, typically red for the penetrant. A more sensitive approach is to use a fluorescent dye (i.e. coumarin, fluorescein) that when illuminated with UV light, highlights surface imperfections, such as cracks and pits, optimally with a greenish-yellow emission. The method is inexpensive requiring only a dilute solution of a small fluorescent dye and a common UV lamp.

Fluorescent indicators were proposed as early warning corrosion detectors by Agarwala. ${ }^{8}$ In recent years, Ming has reported a rhodamine dye (FD1) in an epoxy coating on steel for monitoring $\mathrm{Fe}^{3+9}$ and on aluminum for monitoring $\mathrm{H}^{+} \cdot{ }^{10}$ Dhole has reported an epoxy resin for $\mathrm{Fe}^{2+11}$ and Gao a rhodamine dye (FD2) on T91 steel corrosion. ${ }^{12}$ Wong has used a fluorescein derivative (56CF) on iron for monitoring $\mathrm{H}^{+}$by epi-fluorescence imaging, ${ }^{13}$ and Mokhtari used a 8-hydroxyquinoline to complex $\mathrm{Fe}^{3+}$ in an epoxy coating on ST-37 steel sheets. ${ }^{14}$ Crespy used mesoporous silica nanocapsules on 304 stainless steel. ${ }^{15}$ The Battelle Smart Corrosion Detector $^{\circledR}$ microbeads, when mixed into coatings, mitigate and detect corrosion, as does a smart-sensing polymer coating by $\mathrm{Li}^{16}$ Each of these examples detects a single chemical species.

The field of molecular-logic based computation, including the detection of two or more chemical species, is progressing towards applications at interfaces and on solid surfaces. ${ }^{17}$ 
Recent advancements include luminescent hydrogels, ${ }^{18}$ edgedetection kits, ${ }^{19}$ polymeric thermometers, ${ }^{20}$ redox-active logic gate films ${ }^{21}$ and logic-tagged polymer beads. ${ }^{22,23}$ From a Boolean logic perspective, the LPT method of using a fluorescent dye to expose cracks and pits corresponds to PASS 1 logic. $^{23 a}$ Chemical sensors that communicate a fluorescence response on detection of a single analyte (i.e. $\mathrm{H}^{+}, \mathrm{Fe}^{2+}, \mathrm{Fe}^{3+}, \mathrm{Al}^{3+}$ ) by a turn-on or turn-off response emulate Boolean $\mathrm{YES}^{23 b}$ or NOT logic. ${ }^{23 c}$ Taken together the two studies by Ming ${ }^{9,10}$ with FD1 construe non-selective $\mathrm{H}^{+}, \mathrm{Fe}^{3+}$-driven OR logic. ${ }^{17}$

Our goal has been to sense two corrosion markers simultaneously, notably acidity $\left(\mathrm{H}^{+}\right)$and oxidisability $\left(\mathrm{Fe}^{3+}\right) \cdot{ }^{24}$ The result is improved selectivity, and less chance of a false positive result. We call these molecules Pourbaix sensors, in honour of Marcel Pourbaix, the inventor of the pH-potential (pE) diagram. ${ }^{25}$ These molecules monitor the $\mathrm{pE}$ and $\mathrm{pH}$ by emitting an optical signal. Our first prototypes, designed according to an AND logic function, were anthracene-based molecules with two photoinduced electron transfer (PET) switching mechanisms, ${ }^{26}$ while our second generation prototypes were based on 4-amino1,8-naphthalimide with PET and non-emissive twisted internal charge transfer (TICT) switching mechanisms. ${ }^{27,28}$ We have extended the concept to polymer beads, ${ }^{2,23} \mathrm{H}^{+}, \mathrm{Fe}^{3+}$-driven INHIBIT logic gates based on 1,3,5-triaryl-2-pyrazolines, ${ }^{29}$ and $\mathrm{H}^{+}, \mathrm{Fe}^{3+}, \mathrm{Na}^{+}$-driven three-input logic gates in solution. ${ }^{30}$

In this paper we present perylenediimide (PDI)-based fluorescent AND logic gates. Symmetrical fluorescent PDI $\mathrm{pH}$ indicators, ${ }^{31}$ with two aliphatic or aromatic amines, ${ }^{32}$ or redox indicators $^{33}$ with two ferrocenes are known. ${ }^{34,35}$ Asymmetrical PDI switches with different moieties at opposite ends of the PDI scaffold are far less common as they are more synthetically demanding. ${ }^{36}$ Molecules 1 and 2 are designed with an 'electron-

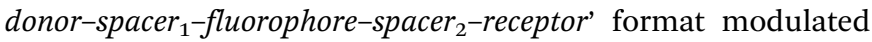
by two PET switching mechanisms (Fig. 1). ${ }^{24,27}$ On one end of the PDI fluorophore is an electron donor (ferrocene), and at the other end, a proton receptor (dimethylamino 1 or morpholine 2) connected by methylene and ethylene spacers, respectively. Upon oxidation of ferrocene by $\mathrm{Fe}^{3+}$, and protonation of the tertiary amine by $\mathrm{H}^{+}$, an enhanced fluorescence was expected.
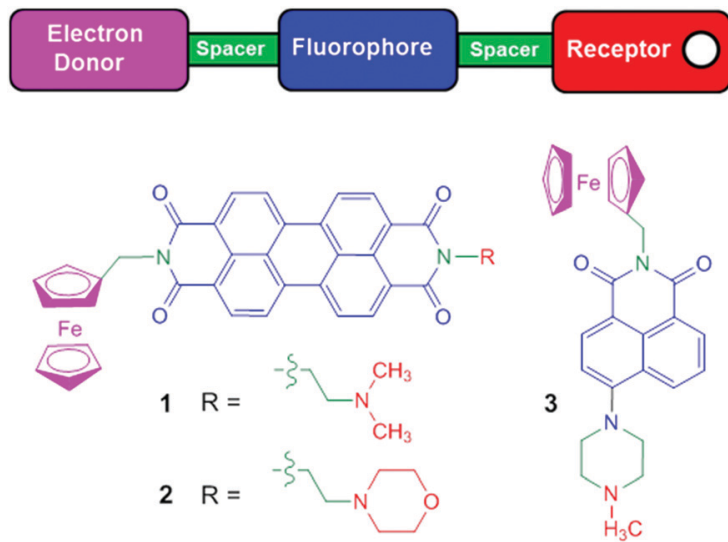

Fig. 1 The colour-coded schematic of the design concept and the chemical structures of Pourbaix sensors 1-3.
In the absence of either (or both) chemical inputs, PET from either the ferrocene or the amine would render no fluorescence. We include tests with 3, our current state-of-the-art in Pourbaix sensor technology endowed with PET and ICT mechanisms. ${ }^{37,38}$ We now present the first molecular-logic based approach to the early detection of corrosion in a polyurethane coating on mild steel using Pourbaix sensors.

\section{Results and discussion}

\section{Synthesis and characterisation}

Logic gates 1 and $\mathbf{2}$ were synthesised by a multi-step procedure (Scheme 1). ${ }^{37}$ Perylene-3,4,9,10-tetracarboxylic dianhydride was dissolved in aqueous $\mathrm{KOH}$ solution and converted to the quadruple negatively charged 1,3,4,10-perylenetetracarboxylate. Subsequent addition of $1 \mathrm{M} \mathrm{HCl}$ provided the monopotassium perylenediimide salt in $96 \%$ yield. Condensation with $\mathrm{N}, \mathrm{N}$ dimethylethane-1,2-diamine or 2-morpholinoethylamine gave the perylene monoimide monohydrides in $96 \%$ and $52 \%$ yield, respectively. Reaction with ferrocenylmethylamine in neat quinoline and zinc acetate at $160{ }^{\circ} \mathrm{C}$ provided 1 and 2 in $35 \%$ and $31 \%$ yield, respectively. ${ }^{34}$ The synthesis of 3 was reported in a previous study. ${ }^{27}$

Compounds $\mathbf{1}$ and $\mathbf{2}$ are insoluble in dichloromethane, diethyl ether, pentane, hexane and chloroform; poorly soluble in methanol, ethanol, acetonitrile, ethyl acetate and water; and slightly soluble in DMSO, THF, benzene and quinoline. The compounds were characterised by ${ }^{1} \mathrm{H}$ NMR, FTIR, HRMS and optical spectroscopies. Synthetic procedures and experimental data are available in the ESI. $\dagger$

The UV-visible absorption and fluorescence spectroscopic studies were performed in tetrahydrofuran (THF) for comparison with other PDI molecular switches in the literature. ${ }^{30}$ Solutions of $10^{-6} \mathrm{M} 1$ and 2 are red and orange under room lighting (Fig. 2a). The UV-vis absorption spectra have welldefined $\pi \rightarrow \pi^{*}$ electronic transitions typical of the PDI fluorophore with bands centred at $455 \mathrm{~nm}, 485 \mathrm{~nm}$ and $521 \mathrm{~nm}$. Titration with up to $1 \mathrm{mM}$ acid or $100 \mu \mathrm{M} \mathrm{Fe}^{3+}$ showed no significant changes in the $\lambda_{\max }$ consistent with the modular format as the substituents at the $N$-positions have negligible

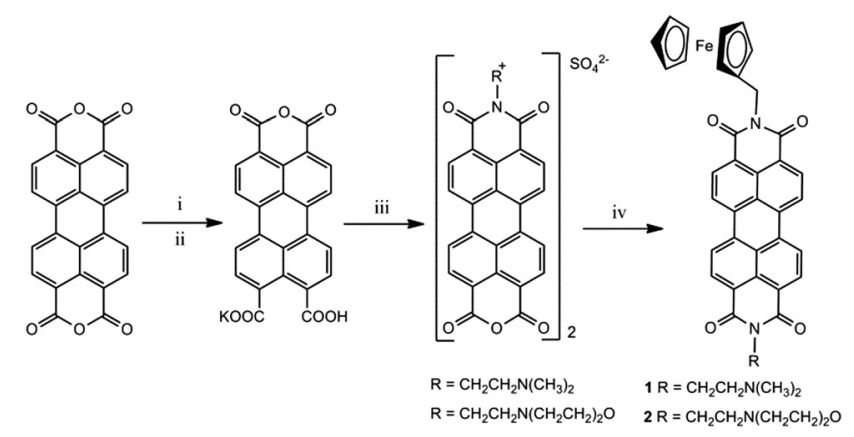

Scheme 1 The synthesis of Pourbaix sensors 1 and 2. Reagents, yield: (i) $1 \mathrm{M} \mathrm{KOH}, 100 \%$ (ii) $1 \mathrm{M} \mathrm{HCl}, 96 \%$ (iii) $\mathrm{N}, \mathrm{N}$-dimethylethane-1,2-diamine, $96 \%$ or 2-morpholinoethylamine, 52\%, $\mathrm{H}_{2} \mathrm{O}, 0.5 \mathrm{M} \mathrm{H}_{2} \mathrm{SO}_{4}$ (iv) $\mathrm{FCCH}_{2} \mathrm{NH}_{2}$, $\Delta$, quinoline, $\mathrm{Zn}(\mathrm{OAc})_{2}, 35 \%$ and $31 \%$ to yield 1 and 2 , respectively. 


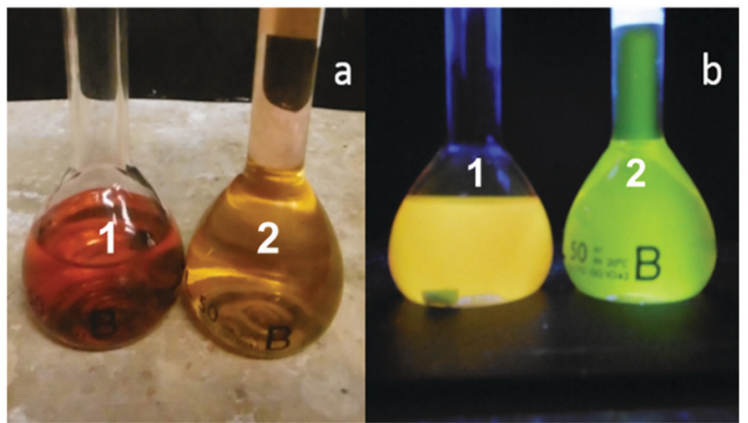

Fig. 2 Solutions of $10^{-6} \mathrm{M} 1$ and 2 in the presence of $80 \mu \mathrm{M} \mathrm{H}^{+}$and $80 \mu \mathrm{M}$ $\mathrm{Fe}^{3+}$ in THF (a) under ambient light and (b) under a handheld UV lamp at $365 \mathrm{~nm}$ light in a dark cabinet.

effect on the absorption properties. In the ground state, the methylene and ethylene spacers serve their intended purpose to isolate the electron-rich ferrocene and tertiary amines from the PDI core. These results validate $\mathbf{1}$ and $\mathbf{2}$ as ideal PET fluorescence systems. $^{38}$

Upon irradiation with $365 \mathrm{~nm}$ UV light, neat THF solutions of $10^{-6} \mathrm{M} 1$ and 2 are non-fluorescent, but on addition of both $\mathrm{H}^{+}$and $\mathrm{Fe}^{3+}$ a bright yellow fluorescence is observed for $\mathbf{1}$, and a green fluorescence for 2 (Fig. 2b), which are ideal colours for non-destructive LPT corrosion detection. ${ }^{1}$ The emission of 1 and 2, excited at $490 \mathrm{~nm}$, are nearly identical mirror images to the UV-vis spectra with two $\lambda_{\text {flu }}$ at $531 \mathrm{~nm}$ and $570 \mathrm{~nm}$. A small Stokes shift of $325 \mathrm{~cm}^{-1}(9 \mathrm{~nm})$ and $470 \mathrm{~cm}^{-1}(13 \mathrm{~nm})$ separates the peak maxima between $S_{0} \rightarrow S_{1}$ absorption and $S_{1} \rightarrow S_{0}$ emission transitions for $\mathbf{1}$ and $\mathbf{2}$, respectively. The proton binding constants $\left(\mathrm{p} \beta_{\mathrm{H}^{+}}\right)$, the concentration at which half the proton receptor is protonated, are 3.5 and 5.4, and the fluorescence enhancement (FE), the ratio between the highest to second highest fluorescence intensities, are 3.8 and 3.5.

Dilute THF solutions of 3 are colourless, but emit a green fluorescence in the presence of $\mathrm{H}^{+}$and $\mathrm{Fe}^{3+}$. The $\lambda_{\text {abs }}$ at $396 \mathrm{~nm}$ undergoes a blue-shift to $379 \mathrm{~nm}$ on addition of $\mathrm{H}^{+}$due to the TICT state on protonation of the methylpiperazine with a single $\lambda_{\text {flu }}$ at $492 \mathrm{~nm}$; consequently, the Stokes shift is significantly larger at $6060 \mathrm{~cm}^{-1}(113 \mathrm{~nm})$. The $\mathrm{p} \beta_{\mathrm{H}^{+}}$and $\mathrm{FE}$ of 3.5 and 4.0 are in agreement with those of $\mathbf{1}$. For comparison, in aqueous methanol 3 has $\lambda_{\text {abs }}$ at $408 \mathrm{~nm}$ and $385 \mathrm{~nm}$ in the absence and presence of $\mathrm{H}^{+}$, and $\lambda_{\text {flu }}$ at $528 \mathrm{~nm}$ with a Stokes shift of $7035 \mathrm{~cm}^{-1}(143 \mathrm{~nm})$, respectively. ${ }^{27}$ Due to the different media, the $\mathrm{p} \beta_{\mathrm{H}^{+}}$and FE are significantly different at 7.7 and 13 . Table 1 provides a summary of optical data for 1-3.

Molecules 1 and 2 function as fluorescent $\mathrm{H}^{+}, \mathrm{Fe}^{+}$-driven AND logic gates. A bright fluorescence is observed in THF when both $\mathrm{H}^{+}$and $\mathrm{Fe}^{3+}$ are present, while essentially no fluorescence is observed in the absence of both inputs. Addition of $\mathrm{H}^{+}$or $\mathrm{Fe}^{3+}$ results in a weak fluorescence. Representative emission spectra of 1 and 3 under the four input conditions are shown in Fig. 3 and Fig. S1 (ESI $\dagger$ ). The truth table for the digital input-output levels and the fluorescence quantum yields for 1-3 are given in Table 2. Both logic gates switch 'on' with a respectable four-fold contrast ratio and a bright $\Phi_{\mathrm{F}} c a .0 .22$.
Table 1 Optical properties of logic gates 1-3

\begin{tabular}{lllll}
\hline Parameter & $\mathbf{1}^{a}$ & $\mathbf{2}^{a}$ & $\mathbf{3}^{h}$ & $\mathbf{3}^{i}$ \\
\hline$\lambda_{\text {abs }} / \mathrm{nm}^{b}$ & $456,486,522$ & $454,484,519$ & 396 & 408 \\
$\log \varepsilon\left(\mathrm{L} \mathrm{mol}^{-1} \mathrm{~cm}^{-1}\right)^{b}$ & $3.87,4.35,4.54$ & $3.70,3.90,4.11$ & 3.57 & 3.91 \\
$\lambda_{\text {abs }} / \mathrm{nm}^{c}$ & $456,487,522$ & $456,486,521$ & 379 & 385 \\
$\log \varepsilon\left(\mathrm{L} \mathrm{mol}^{-1} \mathrm{~cm}^{-1}\right)^{c}$ & $3.85,4.27,4.39$ & $3.76,3.88,4.00$ & 4.35 & 3.89 \\
$\lambda_{\text {flu }} / \mathrm{nm}^{-1} c d$ & 531,570 & 532,570 & 492 & 528 \\
$\Delta \nu / \mathrm{cm}^{-1 e}$ & 325 & 470 & 6060 & 7035 \\
$\mathrm{p} \beta_{\mathrm{H}^{+}}{ }^{+1}$ & 3.5 & 5.4 & 3.5 & 7.7 \\
$\mathrm{FE}^{g^{\prime}}$ & 3.8 & 3.5 & 4.0 & 13
\end{tabular}

${ }^{a} 10^{-6} \mathrm{M}$ in THF. ${ }^{b}$ Neat solvent. ${ }^{c}$ In presence of $80 \mu \mathrm{M} \mathrm{CH} \mathrm{CH}_{3} \mathrm{SO}_{3} \mathrm{H}$ and $90 \mu \mathrm{M} \mathrm{Fe}\left(\mathrm{ClO}_{4}\right)_{3} \cdot \mathrm{H}_{2} \mathrm{O} .{ }^{d}$ Excitation wavelength $490 \mathrm{~nm}$. Shoulder at $620 \mathrm{~nm} .{ }^{e}$ Stokes shift $\Delta \tilde{\nu}=\tilde{\nu}_{\mathrm{abs}}-\tilde{\nu}_{\mathrm{flu}} \cdot{ }^{f}$ Determined by $\log \left[\left(I_{\max }-I\right) /\right.$ $\left.\left(I-I_{\min }\right)\right]=-\log \left[\mathrm{H}^{+}\right]+\log \beta_{\mathrm{H}^{+}}$in presence of $50 \mu \mathrm{M} \mathrm{Fe}{ }^{3+} \cdot{ }^{g} \mathrm{H}^{+}, \mathrm{Fe}^{3+}-$ induced fluorescence enhancement (FE) ratio of highest to 2nd highest intensities. ${ }^{h}$ In THF excited at $\lambda_{\text {isos }}=385 \mathrm{~nm} .{ }^{i} 1: 1(\mathrm{v} / \mathrm{v}) \mathrm{MeOH} / \mathrm{H}_{2} \mathrm{O}$ excited at $399 \mathrm{~nm}$. Ref. 27.

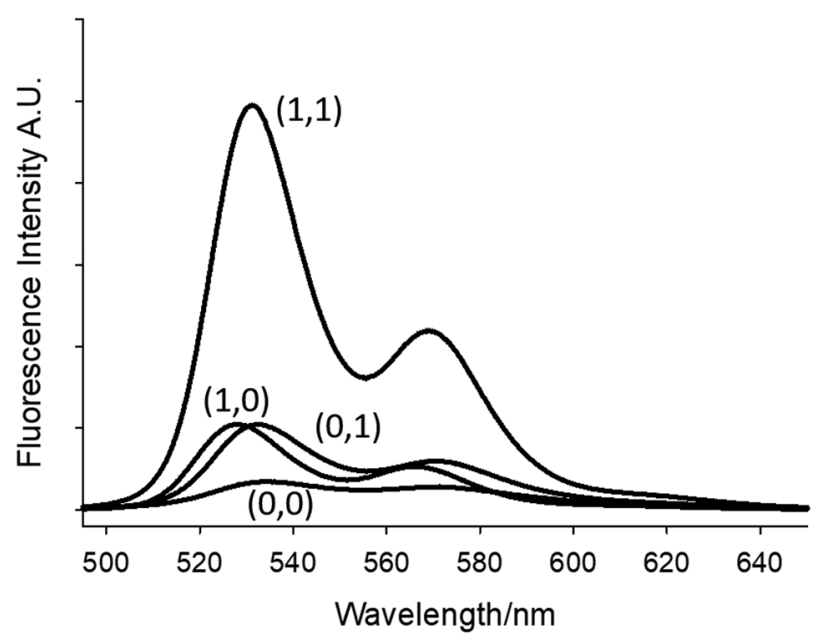

Fig. 3 Fluorescence emission spectra of $10^{-6} \mathrm{M} 1$ in THF excited at $490 \mathrm{~nm}$. High input conditions are $80 \mu \mathrm{M} \mathrm{H}^{+}$and $80 \mu \mathrm{M} \mathrm{Fe}{ }^{3+}$. The numbers in parentheses are the binary input conditions given in Table 2 .

Table 2 Truth tables for AND logic gates 1-3 in $\mathrm{THF}^{\mathrm{a}}$

\begin{tabular}{lllll}
\hline $\begin{array}{l}\text { Input }_{1} \\
\left(\mathrm{H}^{+}\right)^{b}\end{array}$ & $\begin{array}{l}\text { Input }_{2} \\
\left(\mathrm{Fe}^{3+}\right)^{c}\end{array}$ & $\begin{array}{l}\text { Output 1 } \\
\left(\Phi_{\mathrm{F}}\right)^{d}\end{array}$ & $\begin{array}{l}\text { Output 2 } \\
\left(\Phi_{\mathrm{F}}\right)^{d}\end{array}$ & $\begin{array}{l}\text { Output 3 } \\
\left(\Phi_{\mathrm{F}}\right)^{e}\end{array}$ \\
\hline 0 (low) & 0 (low) & 0 (low, 0.018) & 0 (low, 0.017) & 0 (low, 0.007) \\
1 (high) & 0 (low) & 0 (low, 0.044) & 0 (low, 0.055) & 0 (low, 0.009) \\
0 (low) & 1 (high) & 0 (low, 0.052) & 0 (low, 0.065) & 0 (low, 0.068) \\
1 (high) & 1 (high) & 1 (high, 0.20) & 1 (high, 0.22) & 1 (high, 0.27)
\end{tabular}

${ }^{a} 4 \mu \mathrm{M}$ and $8 \mu \mathrm{M} 1$ and 2 excited at $490 \mathrm{~nm}$ and $3 \mu \mathrm{M} 3$ excited at $385 \mathrm{~nm} .{ }^{b}$ For 1,2 and 3 high input $\mathrm{H}^{+}$is $80 \mu \mathrm{M}, 80 \mu \mathrm{M}$, and $10 \mu \mathrm{M}$ added as $\mathrm{CH}_{3} \mathrm{SO}_{3} \mathrm{H}$. Low input $\mathrm{H}^{+}$has no $\mathrm{CH}_{3} \mathrm{SO}_{3} \mathrm{H}$ added. ${ }^{c}$ For $\mathbf{1}, 2$ and 3 high input $\mathrm{Fe}^{3+}$ is $80 \mu \mathrm{M}, 80 \mu \mathrm{M}$ and $10 \mu \mathrm{M} \mathrm{Fe}\left(\mathrm{ClO}_{4}\right)_{3} \cdot \mathrm{H}_{2} \mathrm{O}$. Low input $_{2} \mathrm{Fe}^{3+}$ has no ferric ion salt added. ${ }^{d}$ Quantum yields of $\mathbf{1}$ and 2 versus $10^{-7} \mathrm{M}$ fluorescein in aerated water $0.1 \mathrm{M} \mathrm{NaOH}\left(\Phi_{\mathrm{F}}=0.95\right)$. ${ }^{e}$ Quantum yields versus $10^{-6} \mathrm{M}$ quinine sulfate in aerated $0.1 \mathrm{M} \mathrm{H}_{2} \mathrm{SO}$ $\left(\Phi_{\mathrm{F}}=0.55\right)$. High threshold output level set at $\Phi_{\mathrm{F}}>0.10$.

The driving forces for PET from ferrocene and the amines to the excited state PDI fluorophore are both exergonic at $-1.05 \mathrm{eV}$ and $-0.35 \mathrm{eV}$, respectively. ${ }^{39}$ Due to molecular orbital nodes at 
the nitrogen atoms, the emission wavelength is independent of the $N$-imide substituents, ${ }^{40}$ while the emission intensity is consistent with through-space PET pathways. A significant advantage of these PDI prototypes is that the emission output is beyond $500 \mathrm{~nm}$ so inner filter effects at high $\mathrm{Fe}^{3+}$ concentrations are minimal. Furthermore, spectral overlap between the absorption and emission spectra of PDI, and the absorption spectrum of the radical cation of ferrocene and PDI emission does not occur $\left(\mathrm{Fc}^{\bullet+} \lambda_{\mathrm{abs}}=617 \mathrm{~nm}, \varepsilon=450 \mathrm{M}^{-1} \mathrm{~cm}^{-1}\right.$; $\mathrm{PDI}^{\bullet-}$ $\left.\lambda_{\text {em }}=705 \mathrm{~nm}\right) .{ }^{34}$ Hence, the photophysical and redox properties of the modules are well suited for fluorescence modulation by PET. Furthermore, PDIs have excellent thermal stability and high temperature tolerances, and consequently, they are used in paints and protective coatings in the automotive industry. ${ }^{40}$

\section{Corrosion detection application}

We selected a polyurethane coating prepared by mixing a $3: 1$ (w/w) ratio of Standox Standocryl ${ }^{\circledR}$ VOC-XTRA K9560 and Hardener VOC 20-25 spiked with 2 or 3 dissolved in THF. It is a clear coat lacquer used in the automotive finishing industry. The hardener contains 1,6-hexamethylene diisocyanate and the precursor 2,3-epoxypropyl neodecanoate. We examined the two individual coating components in THF by absorption and fluorescence spectroscopy as background controls. The K9560 component has $\lambda_{\max }$ at $299 \mathrm{~nm}$ and $343 \mathrm{~nm}$ and a broad tail ending at $400 \mathrm{~nm}$ while the hardener has a $\lambda_{\max }$ at $263 \mathrm{~nm}$ and a broad tail out to $310 \mathrm{~nm}$. Irradiation of both colourless solutions with a UV lamp (365 nm) or excitation of THF solutions at $\lambda_{\max }=347 \mathrm{~nm}$ confirmed the coating constituents are transparent and non-fluorescent.

A draw-down coating system was devised comprising of three glass slides, providing a coating with an average thickness of $60 \mu \mathrm{m}$ (see ESI $\dagger$ ). The prepared coupons were air dried for 24 hours, and then scratched with a clean stainless steel scalpel. To accelerate corrosion at the scratched surface, the steel coupons were dipped in $0.5 \mathrm{M} \mathrm{NaCl}$ for a few seconds and allowed to air dry. Magnified emission images of the scratched steel coupons were taken at 0 minutes (before immersion in $\mathrm{NaCl}$ solution), 90 minutes and up to 24 hours.

Fig. 4 shows magnified fluorescence images of a scratch edge on a mild steel coupon coated with a polyurethane coating embedded with Pourbaix sensor 2. The top of the images Fig. 4a-f shows the impregnated coating with 2 and the darker bottom section is the bare steel. More comprehensive sets of results for 2 and 3 are shown in Fig. S2 and S3 (ESI $\dagger$ ). The fluorescence was initiated by excitation with a $488 \mathrm{~nm}$ laser and observed through the eyepiece of the fluorescence microscope. This excitation wavelength was ideal for 2 , but not optimum for 3. Coated steel coupons were exposed to either $0.5 \mathrm{M} \mathrm{NaCl}$ solution (Fig. 4) or deionised (DI) water as a control (Fig. S2 and $\mathrm{S} 3, \mathrm{ESI} \dagger)$. No discernible rust was visible to the naked eye after 90 minutes exposure in $0.5 \mathrm{M} \mathrm{NaCl}$ solution. However, on viewing the surface on irradiation with the $488 \mathrm{~nm}$ laser the onset of corrosion is apparently visible after 90 minutes as a green emission in Fig. 4b (a pinkish colour in the contrast image, Fig. 4e). A large fluorescence enhancement is observed
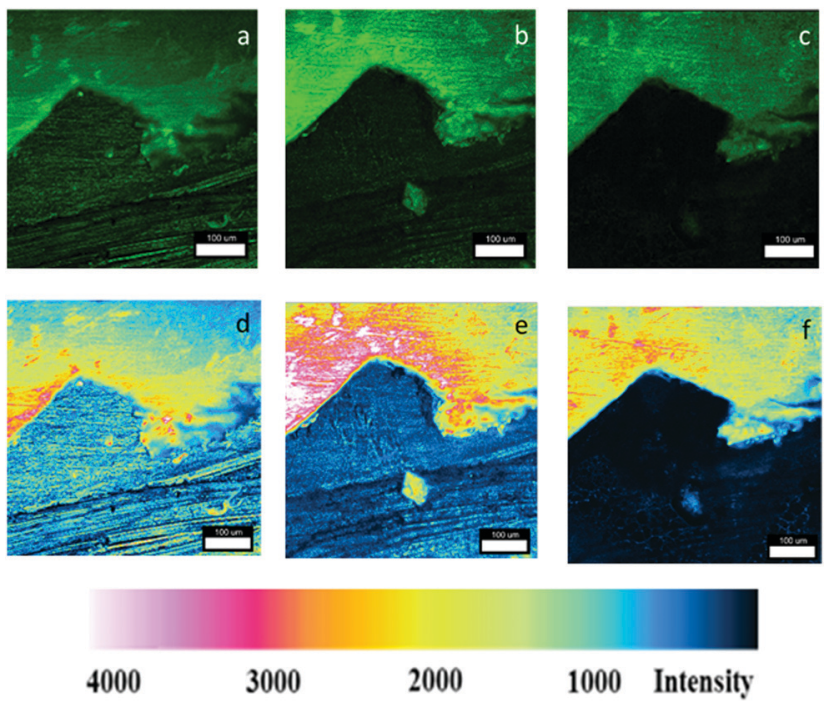

Fig. 4 Confocal fluorescence microscope images $\left(\lambda_{\mathrm{ex}}=488 \mathrm{~nm}\right)$ of scratched polyurethane coated mild steel impregnated with $\mathbf{2}$ after exposure to a $0.5 \mathrm{M} \mathrm{NaCl}$ solution at (a) $0 \mathrm{~min}$ and (b) $90 \mathrm{~min}$; (c) $24 \mathrm{~h}$ and the corresponding enhanced fluorescence contrast images (d)-(f). Concentration of 2 is $13 \mu \mathrm{M} \mathrm{g}^{-1}$. The white bar scale is $100 \mu \mathrm{m}$. Areas shown are magnified images of the enclosed red circles in Fig. 6.
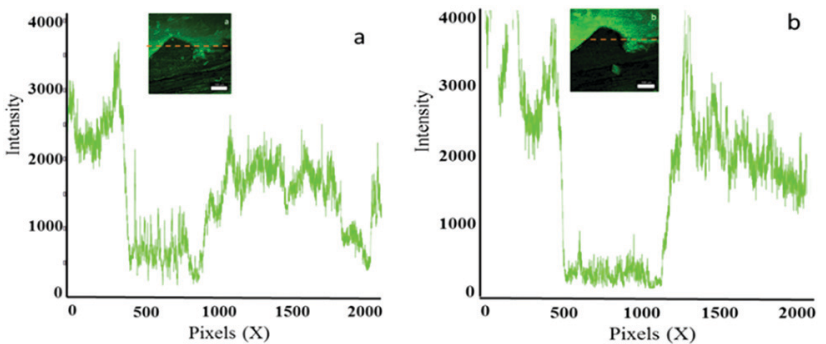

Fig. 5 Fluorescence intensity versus pixels plots of the steel coupon coated with a polyurethane coating impregnated with $\mathbf{2}$ exposed to $0.5 \mathrm{M} \mathrm{NaCl}$ solution after (a) at $0 \mathrm{~min}$ and (b) at $90 \mathrm{~min}$. Inset: Confocal microscope image with an orange dotted line showing area cross section.

exclusively at the polyurethane/scratch interface. This is easily seen from the cross-section fluorescence intensity plots, and notably in the observation of a deeper 'moat' (Fig. 5b) after $90 \mathrm{~min}$. Conversely, the fluorescence barely changes when the scratch-coated coupons are exposed to DI water after 90 minutes. Rust is clearly visible to the naked eye after 24 hours exposure to $0.5 \mathrm{M} \mathrm{NaCl}$ to the detriment of a fluorescence output (Fig. 6c and f). In contrast, no fluorescence is ever observed from the steel coupons exposed to DI after $90 \mathrm{~min}$ and even after 24 hour time period (Fig. S4 and S5, ESI $\dagger$ ). Hence, $\mathbf{2}$ in the polyurethane coating is indeed functioning as an early warning indicator for corrosion in response to an increase in the localised acidity $\left(\mathrm{H}^{+}\right)$and oxidising (liberated $\mathrm{Fe}^{3+}$ ) environment. At subsequent longer time durations, a decrease in fluorescence is observed, which corroborates with published results that the loss of fluorescence intensity is due to the deposition of iron oxide (rust). ${ }^{9}$ This sequence of events 

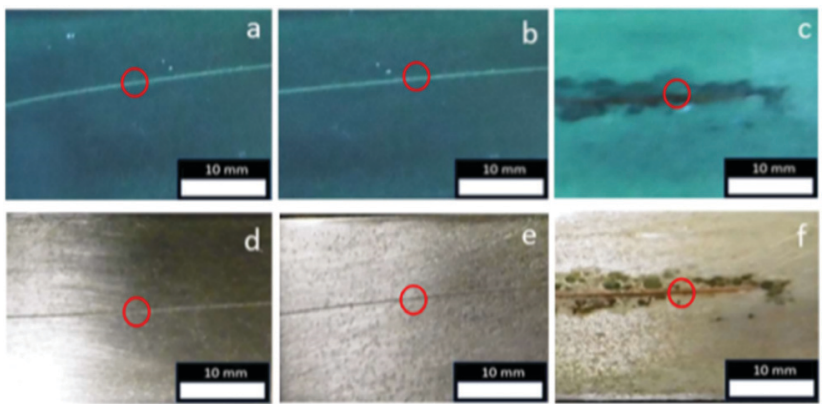

Fig. 6 Digital camera images of scratched metal coupons coated with polyurethane containing 2 under $365 \mathrm{~nm}$ UV light $(\mathrm{a}-\mathrm{c})$ and ambient light (d-f) after exposure to $0.5 \mathrm{M} \mathrm{NaCl}$ solution: (a) and (d) at $0 \mathrm{~min}$; (b) and (e) after $90 \mathrm{~min}$; (c) and (f) after $24 \mathrm{~h}$. The concentration of 2 is $13 \mu \mathrm{M} \mathrm{g}^{-1}$ Magnified images of the enclosed red circles shown in Fig. 4.

is an example of fluorescence modulated off-on-off ternary logic behaviour. ${ }^{18 a, 23 a}$ Without the presence of $\mathrm{NaCl}$ electrolyte corrosion detection and rust deposition will occur over a much longer time frame. No leaching was observed from the polyurethane coating matrix after immersion in DI water after 7 days, which was assessed by fluorescence microscopy. With further refinement, we should be able to increase the fluorescence enhancement and reduced the background fluorescence so that greater image contrast can be observed.

\section{Conclusions}

We have successfully demonstrated, for the first time, the proof-of-concept early detection of corrosion with fluorescent smart molecules for acidity and oxidisability simultaneously. The concept has been validated with molecules featuring a PDI fluorophore incorporating two PET pathways and with a 4-amino-1,8-naphthalimide fluorophore with PET and ICT mechanisms. These two-input AND logic gates emit beyond $500 \mathrm{~nm}$ with a greenish emission at a wavelength longer than earlier prototypes. ${ }^{26,29}$ And we have demonstrated the practical application of Pourbaix sensors immobilised in a polyurethane coating that detects the onset of corrosion by communicating an optical signal before it is visible to the naked eye. These encouraging results from the incorporation of a smart molecule in a coating on a solid material opens up alternative possibilities for the field of logic-based computation and takes us one step further towards a more sustainable future.

\section{Experimental}

Synthetic procedures and characterisation data of $\mathbf{1}$ and $\mathbf{2}$ are available in the ESI. $\dagger$ The synthesis and characterisation of 3 was reported. ${ }^{27}$

\section{Conflicts of interest}

There are no conflicts of interest to declare.

\section{Acknowledgements}

This research was funded by the Endeavour Scholarship Scheme part financed by the EU ESF - Operational Programme II - Cohesion Policy 2014-2020, the TAKEOFF Malta Marittima Proof of Concept Fund (Seed Award 2017) and the University of Malta. Prof. Robert M. Borg is acknowledged for NMR assistance. We thank Ing. Dr Glenn Cassar and James Camilleri for access to the confocal fluorescence microscope.

\section{Notes and references}

1 R. Singh, B. Raj, U. Kamachi Mudali and P. Singh, NonDestructive Evaluation of Corrosion and Corrosion-assisted Cracking, The American Ceramic Society, Wiley, Hoboken, 2019.

2 (a) Tackling Corrosion, ed. E. Silvester, Royal Society of Chemistry, Cambridge, UK, 2020, vol. 10, p. 5; (b) G. Jacobson, NACE International Measures of Prevention, Application and Economics of Corrosion Technology (IMPACT) Study, NACE International, Houston, 2016.

3 J. H. Payer, W. K. Boyd, D. G. Lippold and W. H. Fisher, NBSBattelle Cost of Corrosion Study (\$70 Billion!), Part 1-7, Materials Performance, May-Nov. 1980.

4 (a) National Science Board, Science and Engineering Indicators, January 2018; (b) https://www.whitehouse.gov/wpcontent/uploads/2018/02/ap_18_research-fy2019.pdf.

5 (a) Efforts to Reduce Corrosion on the Military Equipment and Infrastructure of the Department of Defense, 2007, Department of Defense Report (June), Office of the Secretary of Defense, USA; (b) P. Buxbaum, RustBusters, MLF, 2013, 7, March.

6 https://sustainabledevelopment.un.org/.

7 T. R. Witcher, From Disaster to Prevention: The Silver Bridge, Civil Engineering, Reston, Va. Dec. 2017. Silver Bridge was a cantilever suspension bridge built in 1928 connecting Point Pleasant, West Virginia, and Gallipolis, Ohio, over the Ohio River. On Dec. 15, 1967, the bridge collapsed during rush hour traffic, resulting in the death of 46 people. The collapse of the bridge was attributed to failure of an eye bar (a 55-foot-long section of steel, 2 inches thick and 12 inches wide) with a small defect $2.5 \mathrm{~mm}$ (0.1 inches) deep.

8 R. E. Johnson and V. S. Agarwala, Mater. Perform., 1994, 33, 25.

9 A. Augustyniak, J. Tsavalas and W. Ming, ACS Appl. Mater. Interfaces, 2009, 1, 2618.

10 A. Augustyniak and W. Ming, Prog. Org. Coat., 2011, 71, 406. 11 G. S. Dhole, G. Gunasekaran, R. Naik, T. Ghorpade and M. Vinjamur, Prog. Org. Coat., 2020, 138, 105425.

12 T. F. Xia, L. Zhang, D. Q. Zhang and L. X. Gao, J. Chem, 2015, 1.

13 L. Xinjie, H. Spikes and J. S. S. Wong, Corros. Sci., 2014, 87, 118.

14 S. Roshan, A. A. Sarabi Dariani and J. Mokhtari, Appl. Surf. Sci., 2018, 440, 880. 
15 L. Exbrayat, S. Salaluk, M. Uebel, R. Jenjob, B. Rameau, K. Koynov, K. Landfester, M. Rohwerder and D. Crespy, ACS Appl. Nano. Mater., 2019, 2, 812.

16 (a) A. Plaseied, A. Skaja, R. Lalgudi and C. Henderson, Corrosion, 2017, 73, 1091; (b) J.-P. Wang, X. Song, J.-K. Wang, X. Cui, Q. Zhou, T. Qi and G. Liang Li, Adv. Mater. Interfaces, 2019, 190055.

17 (a) A. P. de Silva, Molecular Logic-based Computation, The Royal Society of Chemistry, Cambridge, UK, 2013; (b) S. Erbas-Cakmak, T. Gunnlaugsson, S. Kolemen, T. D. James, A. C. Sedgwick, J. Yoon and E. U. Akkaya, Chem. Soc. Rev., 2018, 47, 2228; (c) T. Sarkar, K. Selvakumar, L. Motiei and D. Margulies, Nat. Commun., 2016, 7, 11374.

18 (a) S. J. Bradberry, J. P. Byrne, C. P. McCoy and T. Gunnlaugsson, Chem. Commun., 2015, 51, 16565; (b) H. Komatsu, S. Matsumoto, S. Tamaru, K. Kaneko, M. Ikeda and I. Hamachi, J. Am. Chem. Soc., 2009, 131(15), 5580.

19 (a) J. Ling, G. Naren, J. Kelly, T. S. Moody and A. P. de Silva, J. Am. Chem. Soc., 2015, 137, 3763; (b) J. Ling, G. Naren, J. Kelly, D. B. Fox and A. P. de Silva, Chem. Sci., 2015, 6, 4472.

20 (a) S. Uchiyama, C. Gota, T. Tsuji and N. Inada, Chem. Commun., 2017, 53, 10976; (b) C.-Y. Yao, S. Uchiyama and A. P. de Silva, Polymers, 2019, 11, 1351; (c) N. Inada, N. Fukuda, T. Hayashi and S. Uchiyama, Nat. Protocol, 2019, 14, 1293.

21 (a) G. de Ruiter and M. E. van der Boom, Acc. Chem. Res., 2011, 44, 563; (b) E. Tartakovsky and M. E. van der Boom, Angew. Chem., Int. Ed., 2008, 47, 5322; (c) G. de Ruiter, L. Motiei, J. Choudhury, N. Oded and M. van der Boom, Angew. Chem., Int. Ed., 2010, 49, 4780.

22 (a) M. Vella Refalo, N. V. Farrugia, A. D. Johnson, S. Klejna, K. Szaciłowski and D. C. Magri, J. Mater. Chem. C, 2019, 7, 15225; (b) M. Vella Refalo, J. C. Spiteri and D. C. Magri, New J. Chem., 2018, 42, 16474.

23 (a) C. Yao, J. Ling, L. Chen and A. P. de Silva, Chem. Sci., 2019, 10, 2272; (b) B. O. F. McKinney, B. Daly, C. Yao, M. Schroeder and A. P. de Silva, ChemPhysChem, 2017, 18, 1760; (c) A. P. de Silva, M. R. James, B. F. McKinney, D. A. Pears and S. M. Weir, Nat. Mater., 2006, 5, 787.

24 (a) D. C. Magri, Chemosensors, 2018, 6(48), 1; (b) D. C. Magri, Supramol. Chem., 2017, 20, 741; (c) D. C. Magri, A. D. Johnson and J. C. Spiteri, J. Fluoresc., 2017, 27, 551; (d) D. C. Magri, Analyst, 2015, 140, 7487; Analyst, 2017, 142, 676.

25 M. Pourbaix, Atlas of Electrochemical Equilibria in Aqueous Solutions, Pregamon Press, Oxford, 1966.

26 (a) T. J. Farrugia and D. C. Magri, New J. Chem., 2013, 37, 148; (b) D. C. Magri, New J. Chem., 2009, 33, 457; (c) D. C. Magri, M. Camilleri Fava and C. J. Mallia, Chem. Commun., 2014, 50, 1009.

27 (a) J. C. Spiteri, J. S. Schembri and D. C. Magri, New J. Chem., 2015, 39, 3349; (b) A. D. Johnson, K. A. Paterson, J. C. Spiteri, S. A. Denisov, G. Jonusauskas, A. Tron, N. D. McClenaghan and D. C. Magri, New J. Chem., 2016, 40, 9917.
28 (a) J. C. Spiteri, S. A. Denisov, G. Jonusauskas, S. Klejna, K. Szacilowski, N. D. McClenaghan and D. C. Magri, Org. Biomol. Chem., 2018, 16, 6195; (b) J. C. Spiteri, A. D. Johnson, S. A. Denisov, G. Jonusauskas, N. D. McClenaghan and D. C. Magri, Dyes Pigm., 2018, 157, 278.

29 G. J. Scerri, M. Cini, J. S. Schembri, P. F. da Costa, A. D. Johnson and D. C. Magri, ChemPhysChem, 2017, $18,1742$.

30 (a) G. J. Scerri, J. C. Spiteri, C. J. Mallia and D. C. Magri, Chem. Commun., 2019, 55, 4961; (b) D. C. Magri and J. C. Spiteri, Org. Biomol. Chem., 2017, 15, 6706; (c) D. C. Magri, M. Camilleri Fava and C. J. Mallia, Chem. Commun., 2014, 50, 1009.

31 (a) N. I. Georgiev, A. I. Said, R. A. Toshkova, R. D. Tzoneva and V. B. Bojinov, Dyes Pigm., 2019, 160, 28; (b) E. Hussain, H. Zhou, N. Yang, S. A. Shahzad and C. Yu, Dyes Pigm., 2017, 147, 211; (c) N. I. Georgiev, A. R. Sakr and V. B. Bojinov, Dyes Pigm., 2011, 91, 332; (d) Y. Ma, F. Zhang, J. Zhang, T. Jiang, X. Li, J. Wu and H. Ren, Luminescence, 2015, 31, 102; (e) R. K. Dubey, G. Knorr, N. Westervelda and W. F. Jager, Org. Biomol. Chem., 2016, 14, 1564.

32 (a) W. E. Ford, J. Photochem., 1986, 34, 43; (b) W. E. Ford, J. Photochem., 1987, 37, 189; (c) G. Schnurpfeil, J. Stark and D. Wöhrle, Dyes Pigm., 1995, 27, 339.

33 (a) C. Wang, W. Tang, H. Zhong, X. Zhang and Y. Shen, J. Heterocycl. Chem., 2009, 46, 881; (b) S. Leroy-Lhez, J. Baffreau, L. Perrin, E. Levillain, M. Allain, M.-J. Blesaand and P. Hudhomme, J. Org. Chem., 2005, 70, 6313; (c) C.-C. You and F. Würthner, J. Am. Chem. Soc., 2003, 125, 9716; (d) B. Xu, C. Wang, W. Ma, L. Liu, Z. Xie and Y. Ma, J. Phys. Chem. C, 2017, 121, 5498.

34 (a) R. Zhang, Z. Wang, Y. Wu, H. Fu and J. Yao, Org. Lett., 2008, 10, 3065; (b) R. Zhang, Y. Wu, Z. Wang, W. Xue, H. Fu and J. Yao, J. Phys. Chem. C, 2009, 113, 2594.

35 M. Supur, M. E. El-Khouly, J. H. Seok, J. Hoon Kim, K.-Y. Kay and S. Fukuzumi, J. Phys. Chem. C, 2010, 114, 10969.

36 P. Yan, M. W. Holman, P. Robustelli, A. Chowdhury, F. I. Ishak and D. M. Adams, J. Phys. Chem. B, 2005, 109, 130.

37 (a) Y. Nagao, Y. Tanabe and T. Misono, Nippon Kagaku Kaishi, 1979, 4, 528; (b) Y. Nagao, N. Ishikawa, Y. Tanabe and T. Misono, Chem. Lett., 1979, 8, 151; (c) M. P. Schmidt and W. Neugebauer, US Pat., 1506545, 1924.

38 B. Daly, J. Ling and A. P. de Silva, Chem. Soc. Rev., 2015, 44, 4203.

39 A. Weller, Pure Appl. Chem., 1968, 16, 115. The driving forces for PET are calculated from $\Delta G_{\mathrm{PET}}=E_{\mathrm{OX}}-E_{\mathrm{RED}}-E_{\mathrm{S}}-e^{2} / \varepsilon r$ where $E_{\mathrm{OX}}$ is the oxidation potential of ferrocene $(0.45 \mathrm{eV})$ or tertiary amine $(1.15 \mathrm{eV}), E_{\mathrm{RED}}$ is the reduction potential of PDI $(-0.96 \mathrm{eV}), E_{\mathrm{S}}$ is the excited state singlet energy of PDI $(525 \mathrm{~nm}, 2.36 \mathrm{eV})$ and $e^{2} / \varepsilon r$ is the coulombic term $(0.10 \mathrm{eV})$. Standard potentials are versus SCE.

$40 \mathrm{~W}$. Herbst and K. Hunger, Industrial Organic Pigments, Wiley-VCH, Weinheim, 2nd edn, 1997. 